\title{
Temperature Variation on Coal Gangue Dumps under the Action of Heat Pipe: Case Study on Yinying Coal Mine in China
}

\author{
Na Zhao \\ Taiyuan University of Technology \\ Yongbo Zhang ( $D$ zhangyongbo2021@sina.com ) \\ Taiyuan University of Technology \\ Jinrong Niu \\ Yangquan Yinying Coal Mine \\ Tong Gao \\ Taiyuan University of Technology

\section{Zhigang Wang} \\ Yangquan Yinying Coal Mine \\ Hong Shi \\ Taiyuan University of Technology
}

\section{Research Article}

Keywords: temperature, coal, gangue, spontaneous, combustion, control, internal, heat

Posted Date: July 9th, 2021

DOI: https://doi.org/10.21203/rs.3.rs-674530/v1

License: (c) (i) This work is licensed under a Creative Commons Attribution 4.0 International License. Read Full License 


\section{Abstract}

Coal gangue in long-term accumulation will often appear spontaneous combustion phenomenon. Generally, the disaster caused by it has always been one of the serious problems threatening the health of residents in the mining area. Master the regularity of deep temperature distribution and eliminate the internal heat is an effective method to control the spontaneous combustion. In this study, using the self-developed heat pipe (HP) and intelligent cloud monitoring software, three groups of single pipe experiments were carried out in different temperature areas of the coal gangue dump in Yinying Coal Mine, to analyze the internal temperature variation under the action of HP. The results show that the temperature is obviously restrained by the HP, and the average cooling range reaches $21.44 \%$ within 700h. However, the temperature of the control group without HP continued to rise by $8 \%$. In the three groups of experiments, the effective control radius of single HP is $3 \mathrm{~m}$. When the depth of gangue is $1 \sim 4 \mathrm{~m}$ and the temperature between $90{ }^{\circ} \mathrm{C} \sim 450{ }^{\circ} \mathrm{C}$, the cooling effect is the best. It revealed that the HP had a substantial effect on thermal removal and inhibited spontaneous coal gangue combustion. In addition, this paper provides a theoretical basis for the HP treatment of spontaneous combustion coal gangue dumps technology.

\section{Background}

Coal gangue is a kind of black argillaceous rock with high ash content, low carbon content and low calorific value, which is harder than coal. The ash content is $40 \% \sim 50 \%$ or more, the carbon content is $10 \% \sim 20 \%$, and the calorific value is as high as $1500 \sim 4700 \mathrm{~kJ} / \mathrm{kg}$. Under the long-term accumulation state, it often has spontaneous combustion $^{1-5}$. China is a big country of coal production and consumption. The emission of coal gangue accounts for about $15 \% \sim 20 \%$ of coal production, and the annual emission is about 280 million tons ${ }^{6}$. According to statistics, the accidents caused by spontaneous combustion of coal gangue account for $50 \%$ of the accidents. The spontaneous combustion of gangue releases a lot of harmful gas, which affects the air quality around the mining area $^{7-9}$. When the combustion exothermic reaction speed is greater than the heat dissipation speed, heat accumulation occurs, and the generated heat and gas rapidly gather in the relatively sealed gangue dump, resulting in the explosion phenomenon, directly endangering the nearby construction facilities and personal safety ${ }^{10,11}$. The prevention and control of spontaneous combustion of coal gangue dump generally starts from combustible materials, oxygen isolation and destruction of heat storage conditions ${ }^{12,13}$. The commonly used methods include grouting glue injection, spraying chemical inhibitor, digging fire source, loess covering, water treatment, inert gas extinguishing and leveling compaction. However, due to the difficulty of heat transfer from the inside of the gangue dump, the gangue dump will still reignite in the long run. Therefore, it is an important research topic in the field of coal gangue dump treatment technology to strengthen the internal heat transfer process of it through economic and rapid technical means.

$\mathrm{HP}$ is a high efficiency heat transfer and heat dissipation element. Its main principle is to use the working medium to absorb and release latent heat of vaporization to transfer heat. The thermal resistance is very small. It can transfer large heat under small temperature difference in a unique heat transfer way to achieve the abnormal heat transfer effect. It has high thermal conductivity, strong adaptability to environment, etc., and it is flexible and convenient to use. In 1965, the author of the Los Alamos laboratory established a complete theory of heat management. At present, the HP technology has been used to recovery and transfer waste heat in the coal fire field, to protect the frozen soil subgrade, low temperature grain storage, desertification control, oil and gas exploitation, and has achieved good results ${ }^{14-18}$. 
The high heat transfer characteristics of HP can effectively restrain the heat transfer coal gangue spontaneous combustion ${ }^{19,20}$. Schmidt et al. ${ }^{21}$ tested the cooling effect of single HP on the fire zone in the fire area of the Wuda Coal field. The temperature of the measuring point at $1.5 \mathrm{~m}$ away from the HP was observed in June from $270{ }^{\circ} \mathrm{C}$ to $250{ }^{\circ} \mathrm{C}$. Since 2014 , the domestic research on the suppression of coal spontaneous combustion by HP has increased gradually. Qurui ${ }^{22}$ proposed the average cooling per hour to evaluate the cooling effect of HP on coal stack, pointed out that reducing the arrangement spacing, increasing insertion depth and reducing the arrangement angle can improve the cooling capacity of the hot rod; Zhang Yaping et al. ${ }^{23}$ analyzed the self-contained coal by HP under different arrangement parameters by changing the layout mode of HP. The relationship between the cooling rate of high temperature heat source point and the liquid filling rate of the HP was established by Wang Liwei ${ }^{24}$.It was found that the cooling capacity of the HP was the best when the liquid filling rate was $40 \%$. Chen Qinghua et al. ${ }^{25}$ pointed out that the HP was affected by the internal gravity and gas-liquid shear force. Fluent simulation results showed that the cooling effect was more significant when the inclination angle was $60^{\circ}$.Deng Jun et al. ${ }^{26-29}$ also carried out a large number of experiments on heat transfer and cooling of coal spontaneous combustion HP, and studied the influence of HP on the temperature field distribution of coal pile by means of experiment and simulation.

The existing research on the technology of HP to treat the spontaneous combustion of coal gangue dumps is mostly limited to the laboratory evaluation and research on the cooling performance of the HP. However, the cooling effect of the HP on the spontaneous combustion area of the coal gangue dumps and the distribution of the internal horizontal and vertical temperature under the action of the HP are not clear. Therefore, the author studies the cooling effect of HP in different temperature areas on the coal gangue dump in the Yangquan Yinying Coal Mine based on the HP and wireless temperature data acquisition and transmission cloud platform system, and provides guidance for the HP in the field of prevention and control of spontaneous combustion of coal gangue.

\section{Experiment And Methodology}

Experimental background. The Yinying Coal Mine in Yangquan City of Shanxi Province is located $11.5 \mathrm{~km}$ to the northwest of Yangquan City. The industrial site of the mine is located in the gunpowder ditch about $1.5 \mathrm{~km}$ in the north of Yinying town. The main coal seam is No.15 coal. At present, the annual production design capacity and washing capacity has reached 2.4 million tons, and the output of gangue is about 400000 tons/year. The gangue dump of Yinying Coal Mine studied in this paper has been accumulating gangue since 1994. It is located on the east side of the industrial site. All the gangues are layered from the bottom of the upper slope to the top. The $8 \mathrm{~m}$ high gangue is divided into one layer, which is divided into one, two and three platforms (as shown in Fig 1), covering an area of about $16.3 \mathrm{hm}^{2}$. In 2006, the first spontaneous combustion occurred in the gangue dump, and then the surface of the gangue was covered with about $0.5 \mathrm{~m}$ loss layer, and greening measures were taken. In 2018, the area of returning is about $2600 \mathrm{~m}^{2}$, causing the decline of vegetation on the surface.

The climate of the study area is continental monsoon climate, warm temperate semi-arid climate. The climate is characterized by four distinct seasons, drought in spring, more wind and less rain; hot in summer, more rainfall; cool in autumn, humid and rainy; cold and dry in winter. The annual average temperature is $9.1^{\circ} \mathrm{C}$, the extreme minimum temperature is $-20.5^{\circ} \mathrm{C}$, the extreme maximum temperature is $40{ }^{\circ} \mathrm{C}$; January is the coldest, the average temperature is $-5.9^{\circ} \mathrm{C}$, July is the hottest, the average temperature is $22.1^{\circ} \mathrm{C}$, the annual temperature range is large, the average temperature is $28.0^{\circ} \mathrm{C}$; The annual average atmospheric pressure is $907.8 \mathrm{hpa}$; the annual average precipitation is $562.8 \mathrm{~mm}$, the annual average evaporation is $1880.1 \mathrm{~m}$, which is 3.55 times of the precipitation. 
Working principle of HP. The HP is a kind of high efficiency heat conduction device made of carbon seamless steel pipe. The inner hollow is sealed with inorganic medium, and has unique one-way heat conduction performance. It is a phase change cooling technology based on evaporation and condensation of liquid working medium and carrying a lot of heat ${ }^{30,31}$.

The total length of the HP is $5 \mathrm{~m}$ and the pipe diameter is $76 \mathrm{~mm}$. The HP can be divided into two sections, condensation section and evaporation section (as shown in Fig2). During the operation of the HP, the internal working medium absorbs heat through the pipe wall of the condensation section, and evaporates to the condensation section under the action of the small pressure difference between the evaporation section and the condensation section. The working medium contacts the cooler pipe wall in the condensation section, releases the latent heat of vaporization and condenses into liquid. Under the action of gravity, the working medium flows back to the evaporation section along the pipe wall to complete the whole heat transfer cycle process. The heat source in the coal gangue dumps can be transmitted to the atmosphere continuously, and the heat loss in the high temperature area inside it can be accelerated to achieve the purpose of cooling.

Experimental methods and process. Three groups of single tube tests were carried out in the relatively high temperature area, medium temperature area and low temperature area of the gangue dump in Yinying Coal Mine. A $\mathrm{HP}$ and several temperature measuring tubes were installed in three temperature zones, and a $3 \mathrm{~m}$ deep temperature measuring tube was installed in the low temperature zone as the control group.

The HP was embedded in the coal gangue dump by drilling first and then intubation. The length of the HP is $5 \mathrm{~m}$, the buried depth of it is $3.5 \mathrm{~m}$, and the length of it is $1.5 \mathrm{~m}$ in the air. Wireless transmission K-type high temperature thermocouple (armored) temperature measuring equipment is installed at 1, 2 and $3 \mathrm{~m}$ along the $120^{\circ}$ direction around the HP. The collected data are received from lora4g gateway, processed by SaaS cloud service platform and transmitted to mobile phone and PC display terminal (as shown in Fig 3), so as to monitor the field temperature test data in real time. Fig 4 illustrates the arrangement of HP201 and its temperature measuring points. According to the situation of the coal gangue dump, temperature monitoring was carried out in three groups of single pipe experiments areas to study the response of the internal temperature field of coal gangue dump to HP.

\section{Results And Discussion}

\section{Results and discussion}

Initial temperature. According to the statistics of the initial temperature of three groups of single tube test areas, the analysis of Tab 1 shows that the temperature of HP122 test area is the lowest, and the highest temperature is at T204-8, which reaches $169.2^{\circ} \mathrm{C}$. The temperature of $1 \sim 5 \mathrm{~m}$ is below $90{ }^{\circ} \mathrm{C}$, and the temperature of 6 and $7 \mathrm{~m}$ is 96.5 ${ }^{\circ} \mathrm{C}$ and $105.6^{\circ} \mathrm{C}$ respectively, which starts to accelerate oxidation; the temperature of HP201 test area is above 90 ${ }^{\circ} \mathrm{C}$, and the temperature of $1 \mathrm{~m}$ and $2 \mathrm{~m}$ underground is rapid oxygen in the chemical zone, the temperature at $3 \mathrm{~m}$ underground reaches above $350{ }^{\circ} \mathrm{C}$, and the temperature at $5 \mathrm{~m}$ and $6 \mathrm{~m}$ underground reaches the highest; in the HP168 test zone, the temperature at $1 \mathrm{~m}$ is below $90^{\circ} \mathrm{C}$, the temperature at $2 \mathrm{~m}$ and $3 \mathrm{~m}$ is the rapid oxidation zone, the temperature at T304- 4 reaches $432.5^{\circ} \mathrm{C}$, and the temperature at T304-7 reaches the highest, $572.5^{\circ} \mathrm{C}$, followed by $\mathrm{T} 304-8,544.2^{\circ} \mathrm{C}$.

To sum up, the gangue in HP122 test area is in the oxidation stage, and there is no spontaneous combustion phenomenon. HP201 and HP168 test areas start spontaneous combustion at the depth of 3m and 4m respectively, and reach the highest temperature at $6 \mathrm{~m}$ and $7 \mathrm{~m}$ respectively. This is because the buried depth of 1 and $2 \mathrm{~m}$ is easy 
to conduct heat conduction with the external environment, and the heat is easy to dissipate. The greater the buried depth of gangue, the easier the heat is to accumulate and difficult to dissipate, resulting in higher temperature.

Comparison between HP and without HP data. Take HP122 group test as an example, compare the control group with $3 \mathrm{~m}$ depth and without HP, draw the temperature change diagram from HP installation to 700h, as shown in Fig 5.

It can be seen from Fig. 5 (a) 5 (d) that the existence of HP has a great influence on the internal temperature change of coal gangue dump. In the case of no HP, the temperature of the gangue dump at this location increases from $66^{\circ} \mathrm{C}$ to $71.7^{\circ} \mathrm{C}$ within $700 \mathrm{~h}$, and the temperature rises by $5.7{ }^{\circ} \mathrm{C}$ with a large temperature change slope; while the temperature at T201-3, which is $0 \mathrm{~m}$ away from the HP, decreases from $69.5^{\circ} \mathrm{C}$ to $42.5^{\circ} \mathrm{C}$ within $700 \mathrm{~h}$, and the temperature is in a state of continuous decline. The temperature of T202-3 in figure (b) rises from $72.2^{\circ} \mathrm{C}$ to $74.5^{\circ} \mathrm{C}$ at a horizontal distance of $1 \mathrm{~m}$ from the $\mathrm{HP}$, and then continues to drop to $55^{\circ} \mathrm{C}$. After $100 \mathrm{~h}$, the temperature of T205-3 continues to drop by $13.5^{\circ} \mathrm{C}$. The temperature of T203-3 temperature measuring point in figure (c) fluctuates from $70.5{ }^{\circ} \mathrm{C}$ to $74.2^{\circ} \mathrm{C}$ at a distance of $2 \mathrm{~m}$ from the HP horizontally, and then decreases continuously after $100 \mathrm{~h}$, which indicates that the heat transfer of the HP has stabilized at this time, with a decrease of $17.7 \%$; the temperature of T206-3 temperature measuring point in figure (c) decreases from $79.5^{\circ} \mathrm{C}$ to $70.3^{\circ} \mathrm{C}$ within $700 \mathrm{~h}$, with a decrease of $9.2{ }^{\circ} \mathrm{C}$. The temperature measurement point T204-3 in figure (d) fluctuates from $73{ }^{\circ} \mathrm{C}$ to $75{ }^{\circ} \mathrm{C}$ at $3 \mathrm{~m}$ away from the HP, and then continues to drop to $60^{\circ} \mathrm{C}$.

To sum up, it can be seen that: (1) in the low-temperature oxidation zone where the temperature of gangue dump is below $90{ }^{\circ} \mathrm{C}^{32-34}$, after the HP has been running for $700 \mathrm{~h}$, the temperature is in a state of continuous decline, and the temperature change slope is large, while the temperature of the control group without HP is in a state of continuous rise. (2) It takes about 100 hours for the HP to reach a stable heat transfer state. (3) The HP heat transfer has a certain disturbing effect on the temperature of the coal gangue dump, and accelerates the heat dissipation of it. The average cooling range at $3 \mathrm{~m}$ underground is $21.44 \%$, which effectively reduces the internal temperature of the study area. (4) It can be considered that the effective radius of the HP is $3 \mathrm{~m}$ in the low temperature oxidation zone below the critical temperature point $\left(80 \sim 90^{\circ} \mathrm{C}\right)$.

Horizontal temperature variation. In order to study the horizontal temperature distribution characteristics of Gangue Mountain under the action of HP, taking HP201 test as an example, using the temperature data series collected by each temperature measurement point in the test, draw the contour map of horizontal temperature distribution in different depth inside the gangue mountain before and after installing the HP, as shown in Fig 6.

It can be seen that: (1) the overall distribution of temperature in the study area is that the temperature in the southeast is higher than that in the northwest. (2) The internal temperature distribution of gangue increases from top to bottom, and the temperature distribution of each layer is uniform without temperature concentration point. (3) The temperature at 5 and $6 \mathrm{~m}$ is the highest because the temperature at 1 and $2 \mathrm{~m}$ away from the ground can be heat transferred with the external temperature, and a part of the heat is dissipated by itself, and the temperature in the deep is not easy to spread to the outside, which leads to the formation of heat storage area.

After 90 days of continuous operation of HP, the temperature inside the coal gangue dump at $1 \sim 6 \mathrm{~m}$ underground decreased to varying degrees. Among them, the cooling effect of shallow depth is the most obvious, and the influence of the disturbance action of HP is also used in the depth of 5 and $6 \mathrm{~m}$. The heat flux has changed, which indicates that the temperature of $6 \mathrm{~m}$ can be disturbed when the buried depth of the HP is $3.5 \mathrm{~m}$. 
Overall, the HP makes the temperature distribution in the coal gangue dump more uneven, which accelerates the heat dissipation rate and has a high efficiency of heat conduction.

Vertical temperature variation. In order to study the vertical temperature distribution characteristics of coal gangue dump in Yinying Coal Mine under the action of HP, taking HP201 test as an example, the vertical temperature distribution of measuring points is shown in Fig 7.

It can be seen that: (1) with the increase of the depth, the overall temperature has an upward trend, the minimum temperature is $104.7^{\circ} \mathrm{C}$, the maximum temperature is $493.7^{\circ} \mathrm{C}$, and the temperature of $3 \mathrm{~m}$ depth reaches $320{ }^{\circ} \mathrm{C}$, and spontaneous combustion begins ${ }^{35}$. (2) The maximum temperature difference is $191.2{ }^{\circ} \mathrm{C}$ at the depth of 1 and $2 \mathrm{~m}$, and the minimum temperature difference is $3.2^{\circ} \mathrm{C}$ at the depth of 5 and $6 \mathrm{~m}$. This is because, after the gangue spontaneous combustion, part of the heat conduction upward, making the surface temperature rise, part of the heat conduction downward, making the deep gangue temperature rise, and the surface is easy to have heat convection with the outside air and heat dissipation, after a period of time, the surface temperature drops, and the temperature difference between 1 and $2 \mathrm{~m}$ layers becomes larger; at this time, the deep temperature is greater than the shallow temperature, and the internal temperature of the gangue starts from the deep to the surface The temperature difference between 5 and 6 m layers becomes smaller. (3) The trend of vertical temperature at different temperature measuring points is basically the same, which reflects the common characteristics of the relationship between internal temperature and depth of the coal gangue dumps to a certain extent.

After 90 days of continuous operation of the HP, the temperature of the temperature measuring points at $0,1,2$ and $3 \mathrm{~m}$ away from the HP decreases, and the closer the distance is, the better the cooling effect is. After cooling, the lowest temperature is $84.5^{\circ} \mathrm{C}$ and the highest temperature is $473{ }^{\circ} \mathrm{C}$. The cooling range of T102 and T105 is basically the same, and that of T103 and T106 is basically the same. It can be seen from Fig 7 (d) that there is a certain cooling effect at a horizontal distance of $3 \mathrm{~m}$, but the cooling effect is the worst compared with other temperature measuring points, which indicates that the maximum controllable radius of the HP in this area is $3 \mathrm{~m}$.

The maximum drop in different temperature regions. The maximum cooling range of each depth in 90 days in three experimental areas under the action of HP was compared. It can be seen from Fig 8 that the temperature of the three groups of test temperature measuring points decreased in varying degrees. The results show that: (1) the effective cooling radius of the HP in the three temperature zones is $3 \mathrm{~m}$, and the farther the horizontal distance of the HP is, the smaller the cooling range is. (2) The cooling range of the shallow temperature is larger than that of the deep temperature, which is due to: the buried depth of the HP is $3.5 \mathrm{~m}$, the working medium in the evaporation section is $1 \mathrm{~m}$, the buried depth of 1 and $2 \mathrm{~m}$ is easier to dissipate heat; the shallow temperature is easier to form heat convection with the outside world. (3) The gangue layer with the depth of $1-4 \mathrm{~m}$ and the temperature between $90{ }^{\circ} \mathrm{C}$ and $450{ }^{\circ} \mathrm{C}$ has the best cooling effect.

Compared with the three groups of single tube test, HP122 group has the smallest cooling range, which is due to the low initial temperature of the temperature measuring point of this group, which belongs to the low temperature oxidation zone. After 90 days of operation of the HP, the average cooling is $25.6{ }^{\circ} \mathrm{C}$, and the temperature in this zone drops to a more stable range, which greatly reduces the oxidation reaction rate and prevents the possibility of rapid oxidation.

The initial temperature of group $\mathrm{H} 168$ is the highest in three groups, reaching $573{ }^{\circ} \mathrm{C}$, and the cooling range is the largest. This is because: in a platform where group HP201 is located, the temperature in a large area is high, and the vegetation on the surface has withered, with the obvious pungent smell; in some areas of the three platforms where 
group HP168 is located, the temperature is low, the vegetation growth is good, and there are relatively few high temperature concentration points; in the test area of group HP168, the temperature is $1 \sim 4 \mathrm{~m}$ deep This test is a single tube test, which is caused by the limited cooling range.

\section{Conclusion}

In this study, the temperature change and the horizontal and vertical temperature distribution characteristics of coal gangue dump under the action of HP were studied, and the cooling effect of HP on the temperature area of coal gangue dump was systematically discussed. The idea of this study was to provide a theoretical basis for the HP treatment of spontaneous combustion coal gangue dumps technology. The following results can be found from this study:

- The HP has high thermal conductivity and obvious cooling effect on coal gangue dump. In the low-temperature oxidation zone below $80 \sim 90^{\circ} \mathrm{C}$ of gangue dump, compared with the control group without HP, the temperature of the HP decreased continuously after $700 \mathrm{~h}$, and the HP needed a stable period of about $100 \mathrm{~h}$ in the early cooling period, with an average cooling range of $21.44 \%$, while the control group without HP was in a continuous rising state, with a heating range of $8 \%$.

- Under the action of HP, the cooling range of three groups of single pipe test is different, showing a regular change. The internal temperature drop of coal gangue dump is inversely proportional to the horizontal distance and directly proportional to the working time, and the control radius for three groups of tests is $3 \mathrm{~m}$.

- In the vertical direction, the temperature difference between the shallow layer and the deep layer is larger, and the internal temperature is proportional to the depth. The decrease is related to the spontaneous combustion, the depth of the HP, the location of the ignition and the temperature range. The HP mainly reduces the temperature of the gangue layer with the depth of $1 \sim 4 \mathrm{~m}$.

- HP technology has an obvious control effect on different temperature zones of spontaneous combustion coal gangue dump, and can effectively improve the economy of spontaneous combustion treatment of coal gangue dump.

However, there are still some shortcomings in the study, such as the cooling effect of single HP is not as good as that of group pipes, so the optimal arrangement of HPs in different temperature zones of spontaneous combustion coal gangue dump can be further studied.

\section{Declarations}

\section{Author Contributions}

This work was conducted in collaboration of all authors. N.Z., Y.B.Z. and J.R.N. conceived and designed the experiments; N.Z. and Z.G.W., T.G. performed the experiments; N.Z. and H.S. analyzed the data. N.Z. and Y.B.Z. wrote the paper. All authors reviewed the manuscript.

\section{Acknowledgements}

This work was supported by the National Natural Science Foundation of China (41572221) and the National key R \& D projects (Grant number: 2018YFC0406403-4). 


\section{References}

1. Luo, L. et al. Preparation, characteristics and mechanisms of the composite sintered bricks produced from shale, sewage sludge, coal gangue powder and iron ore tailings [J]. Constr Build Mater, 232, 1-8 (2019).

2. He, J. F. et al. Mineralogical characterization of the typical coarse iron ore particles and the potential to discharge waste gangue using a dry density-based gravity separation. Powder Technol, 342, 348-355 (2019).

3. Kuenzer, C. et al. Uncontrolled coal fires and their environmental impacts: Investigating two arid mining regions in north-central China. App/ Geogr, 27, 42-62 (2007).

4. Heffern, E. L. Geologic history of natural coal-bed fires, Powder River basin, USA. Int J Coal Geol, 59, 25-47 (2004).

5. Kong, X. G. et al. Critical slowing down on acoustic emission characteristics of coal containing methane. J Nat Gas Sci Eng, 24, 156-165 (2015).

6. Zhai, X. W. et al. Study and practices on spontaneous combustion control technology of mine coal waste pile [J]. Coal Sci Technol, 043 (004), 53-56 (2015).

7. Pan, R. K. et al. Harm of Gangue Dump and Cause Analysis of Spontaneous Combustion [J]. Saf Environ Eng, 13 (002), 66-70 (2006).

8. Stracher, G. B. Coal fires burning out of control around the world: thermodynamic recipe for environmental catastrophe. Int J Coal Geol, 59, 7-17 (2004).

9. Song, Z. Coal fires in China over the last decade: A comprehensive review [J]. Int J Coal Geol, 133, 72-99 (2014).

10. Zhang, Z. W. Forming Mechanism and Influence Factors of Gangue Hill Spray Explosion[J]. J Liaoning Tec Univ, 1, 11-14 (2002).

11. Wang, J., Zhang, J. \& Zhu, K. Z. L. Anatomy of explosives spontaneous combustion accidents in the Chinese underground coal mine: Causes and prevention. Process Saf Prog, 35, 221-227 (2016).

12. Deng, J. et al. Q., Experimental studies of spontaneous combustion and anaerobic cooling of coal [J]. Fue/157,261-269(2015)

13. Wang, H. et al. Three-dimensional distribution and oxidation degree analysis of coal gangue dump fire area: $A$ case study [J].Science Total Environ772(3),145606(2021)

14. Deng, J. C. et al. Waste heat recovery, utilization and evaluation of coalfield fire applying heat pipe combined thermoelectric generator in xinjiang, china.Energy, 207,118303, (2020).

15. Pan, W. D. et al. Application principle and prospect of thermal-probe technique in cold region engineering. Chinese J Rock Mech Eng, z2, 2673-2676 (2003).

16. Xiu, F. L. et al. Temperature characteristic and inhibition effect on insect pest in grain storehouse based on heat pipe technology [J]. Trans Chinese Soc Agr, Eng14, 264-269 (2013).

17. Chen, X. L. Experiments of lowering the temperature of sandy soil speedily at night by heat-pipe technology [J]. J Huazhong Univ sci tec, 35 (7), 82-88 (2007).

18. Wang, S. Y. et al. Study of Heat Transfer Characteristic in Gravity Heat Pipe of Well bore [J]. Energy Conserv Tec, 31 (1), 46-60 (2013).

19. Yu, F. W. et al. Role of Liquid Filling Ratio on Heat Transfer Characteristics in Miniaturized Gravitational Heat Pipe[J]. J Eng, Thermophys39 (12), 2749-2754 (2018). 
20. Wu, X. D. et al. Laboratory Experiment and Field Test of Gravity Heat Pipe [J]. J Southwest Petrol Univ, 1, 140142 (2008).

21. Schmidt, M. et al. Heat pipes-Suitable for extinguishing underground coal fires? Fed Ministry Edu Res, 2, 433437 (2010).

22. Qu r. Experimental Research of Gravity Heat Pipe used to Extract Spontaneous Heat Storage in the Coal [D] (Energy College of Xi'an University of science and technology, Xi'an, 2014).

23. Zhang, Y. P. et al. Cooling effect analysis of heat pipe suppressing coal spontaneous combustion [J].Coal Eng49(2),100 - 102(2017)

24. Wang, L. W. Study on influence factors of heat transfer capacity of heat pipe used for coal storage pile[D]. Xi'an: School of safety science and engineering, Xi'an University of science and technology(2017)

25. Chen, Q. H. \& Sun, M. H. Influence of Gravity Heat Hipe on Temperature Field in Coal Pile [J]. Saf Coal Mines, 49 (11), 211-214 (2018).

26. Deng, J. \& Li, B. Influence of heat pipes on temperature distribution in coal storage pile [J]. China Saf Sci J, 25 (6), 62-67 (2015).

27. Cheng, F. M. \& Chang, Z. C. Numerical simulation on thermal migration behavior of spontaneous combustion coal pile based on heat pipe cooling technology [J]. J Xian Univ Sci Tec, 4, 581-588 (2019).

28. Li, B. et al. Heat transfer capacity of heat pipes: an application in coalfield wildfire in China [J]. Heat Mass Transf, 54 (6), ,1755-1766 (2018).

29. Deng, J. et al. Combustion properties of coal gangue using thermogravimetry-Fourier transform infrared spectroscopy [J]. Appl Therm Eng, 116, 244-252 (2017).

30. Senthilkumar, R. et al. Comparative study on heat pipe performance using aqueous solutions of alcohols. Heat Mass Transf, 48, 2033-2040 (2012).

31. Shen, C. et al. Experimental investigation on the heat transfer performance of a flat parallel flow heat pipe.Int $J$ Heat Mass Transf168,120856(2021)

32. Lu, P. et al. Experimental research on index gas of the coal spontaneous at low-temperature stage. J Loss Prevent Proc Ind, 17, 243-247 (2004).

33. Smith, M. A. Spontaneous combustion of carbonaceous stockpiles, Part I: the relative importance of various intrinsic coal properties and properties of the reaction system., 84, 1151-1160 (2005).

34. Wu, Y. G. Experimental study on significant gases of coal spontaneous combustion by temperature programmed (TP)-Science Direct [J]. Proc Eng, 26, 120-125 (2011).

35. Cao, K. et al. Prevention and control of coalfield fire technology: A case study in The Antaibao open pit mine goaf burning area, China. Int J Mining. Sci Technol, 22, 657-663 (2012).

\section{Tables}

Tab. 1 Layout plan of temperature measuring tube 


\begin{tabular}{|c|c|c|c|c|c|c|c|c|c|}
\hline \multirow{2}{*}{$\begin{array}{l}\text { No. of } \\
\text { HP }\end{array}$} & \multirow{2}{*}{$\begin{array}{l}\text { No. of } \\
\text { measuring } \\
\text { point }\end{array}$} & \multicolumn{8}{|l|}{ Depth/m } \\
\hline & & 1 & 2 & 3 & 4 & 5 & 6 & 7 & 8 \\
\hline \multirow[t]{6}{*}{ HP201 } & T101 & & & $383.5^{\circ} \mathrm{C}$ & $453^{\circ} \mathrm{C}$ & $485^{\circ} \mathrm{C}$ & $493.7^{\circ} \mathrm{C}$ & & \\
\hline & T102 & $104.7^{\circ} \mathrm{C}$ & $244^{\circ} \mathrm{C}$ & $373.7^{\circ} \mathrm{C}$ & & & & & \\
\hline & T103 & $122.2^{\circ} \mathrm{C}$ & $260^{\circ} \mathrm{C}$ & $394^{\circ} \mathrm{C}$ & & & & & \\
\hline & T104 & $106.2^{\circ} \mathrm{C}$ & $297.4^{\circ} \mathrm{C}$ & $398.2^{\circ} \mathrm{C}$ & $471.2^{\circ} \mathrm{C}$ & $488.5^{\circ} \mathrm{C}$ & $485.2^{\circ} \mathrm{C}$ & & \\
\hline & T105 & $122.2^{\circ} \mathrm{C}$ & $246.7^{\circ} \mathrm{C}$ & $404.7^{\circ} \mathrm{C}$ & & & & & \\
\hline & T106 & $112.2^{\circ} \mathrm{C}$ & $287.3^{\circ} \mathrm{C}$ & $415^{\circ} \mathrm{C}$ & & & & & \\
\hline \multirow[t]{6}{*}{ HP122 } & T201 & & & $64^{\circ} \mathrm{C}$ & $79.5^{\circ} \mathrm{C}$ & $88^{\circ} \mathrm{C}$ & $98^{\circ} \mathrm{C}$ & & \\
\hline & T202 & $47.7^{\circ} \mathrm{C}$ & $65^{\circ} \mathrm{C}$ & $74.5^{\circ} \mathrm{C}$ & & & & & \\
\hline & T203 & $49.7^{\circ} \mathrm{C}$ & $77.2^{\circ} \mathrm{C}$ & $74.2^{\circ} \mathrm{C}$ & & & & & \\
\hline & T204 & $48^{\circ} \mathrm{C}$ & $74^{\circ} \mathrm{C}$ & $71.2^{\circ} \mathrm{C}$ & $76^{\circ} \mathrm{C}$ & $87.2^{\circ} \mathrm{C}$ & $93.2^{\circ} \mathrm{C}$ & $99.7^{\circ} \mathrm{C}$ & $165^{\circ} \mathrm{C}$ \\
\hline & T205 & $46.7^{\circ} \mathrm{C}$ & $63.5^{\circ} \mathrm{C}$ & $71.5^{\circ} \mathrm{C}$ & & & & & \\
\hline & T206 & $60.7^{\circ} \mathrm{C}$ & $79^{\circ} \mathrm{C}$ & $81^{\circ} \mathrm{C}$ & & & & & \\
\hline \multirow[t]{6}{*}{ HP168 } & T301 & & & $260.7^{\circ} \mathrm{C}$ & & & & & \\
\hline & T302 & $84.5^{\circ} \mathrm{C}$ & $141.7^{\circ} \mathrm{C}$ & $254.5^{\circ} \mathrm{C}$ & & & & & \\
\hline & T303 & $94.2^{\circ} \mathrm{C}$ & $157.5^{\circ} \mathrm{C}$ & $251^{\circ} \mathrm{C}$ & & & & & \\
\hline & T304 & $101.7^{\circ} \mathrm{C}$ & $156.5^{\circ} \mathrm{C}$ & $262^{\circ} \mathrm{C}$ & $442.7^{\circ} \mathrm{C}$ & $528.7^{\circ} \mathrm{C}$ & $550.2^{\circ} \mathrm{C}$ & $573^{\circ} \mathrm{C}$ & $545^{\circ} \mathrm{C}$ \\
\hline & T305 & $92^{\circ} \mathrm{C}$ & $145.7^{\circ} \mathrm{C}$ & $238^{\circ} \mathrm{C}$ & & & & & \\
\hline & T306 & $101.2^{\circ} \mathrm{C}$ & $175.5^{\circ} \mathrm{C}$ & $298.2^{\circ} \mathrm{C}$ & & & & & \\
\hline
\end{tabular}

Figures 


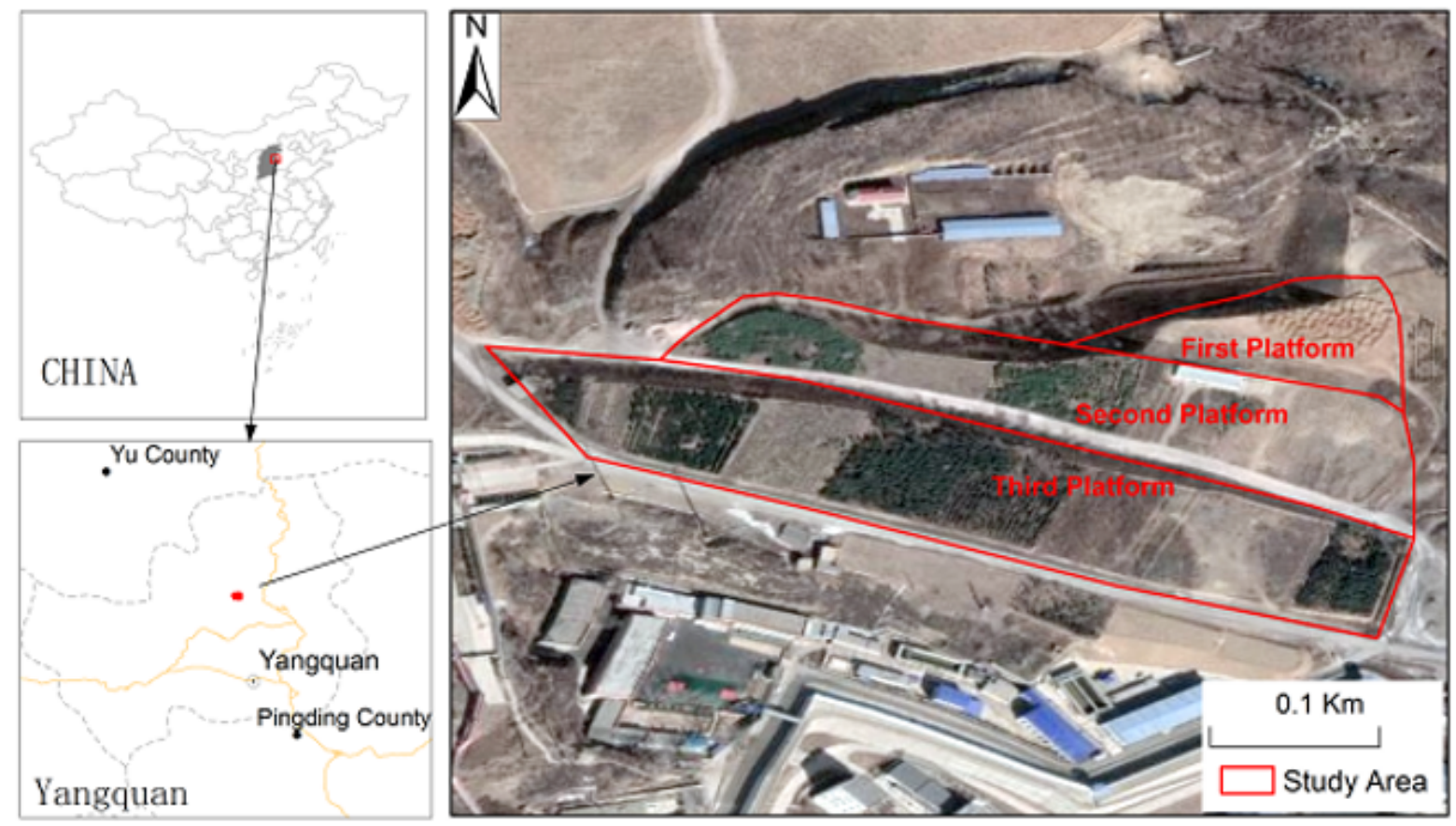

Figure 1

The location of study area

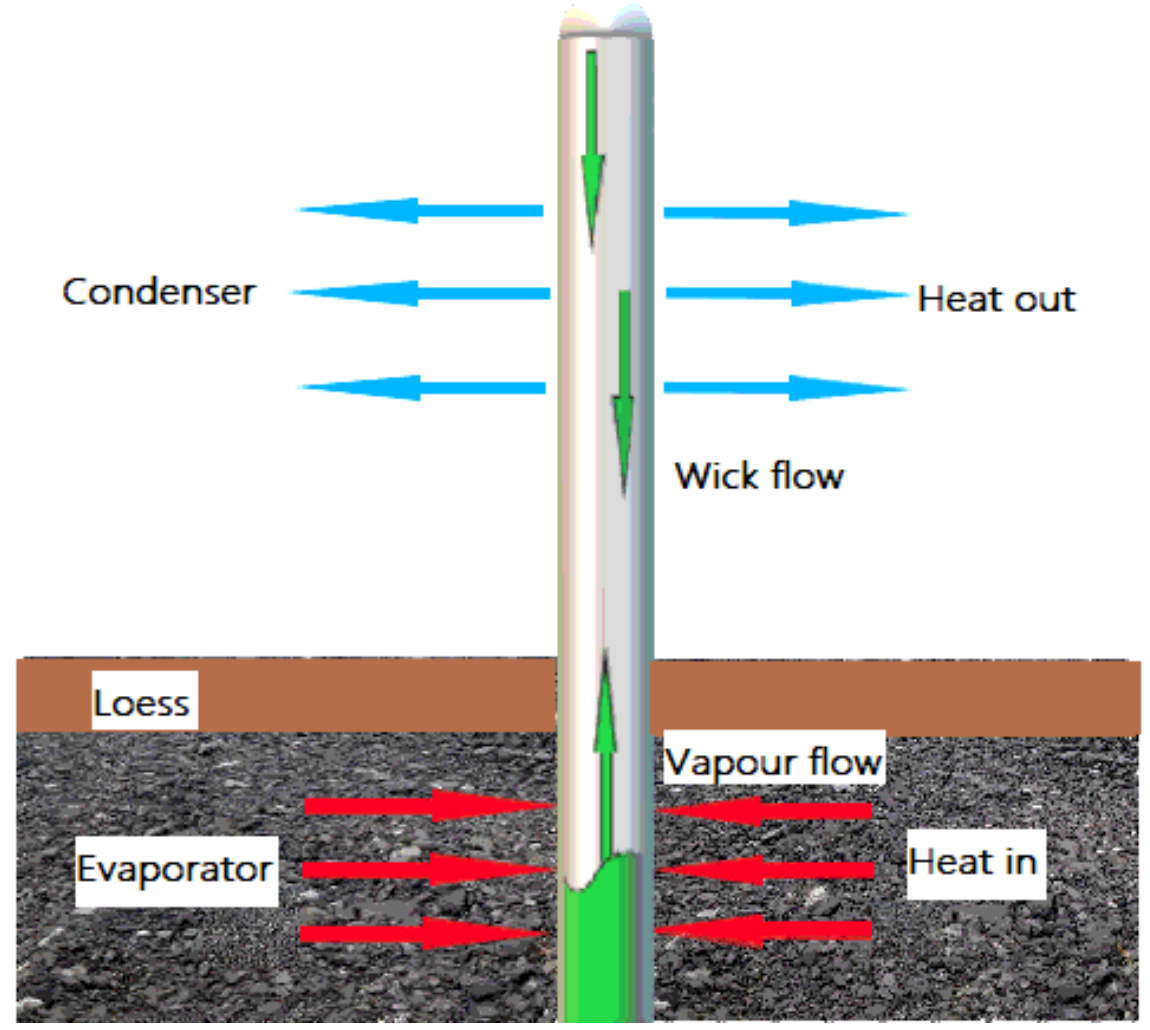

\section{Figure 2}

Schematic diagram of the working principle of the HP 

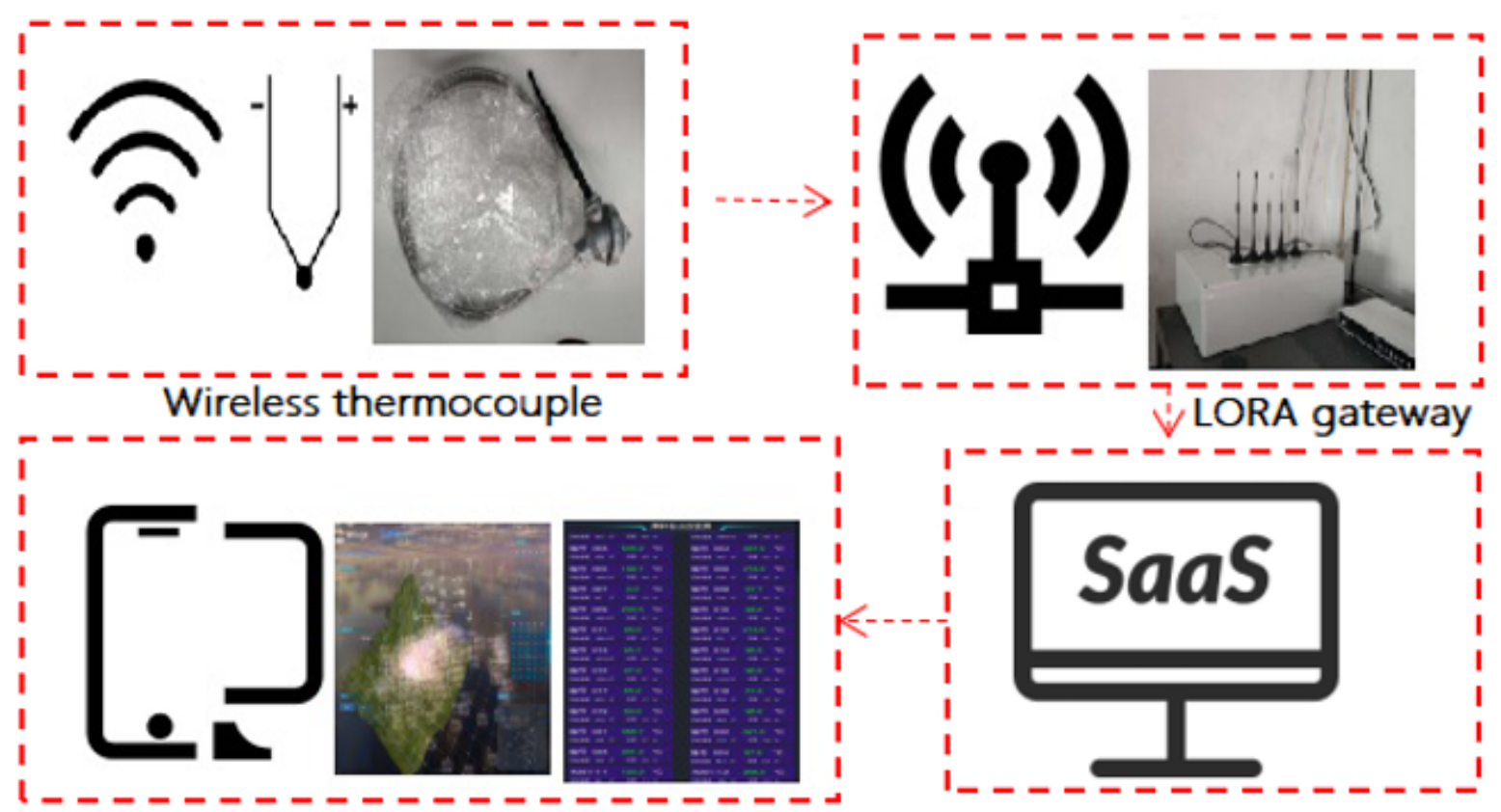

$\mathrm{PC}$ and mobile

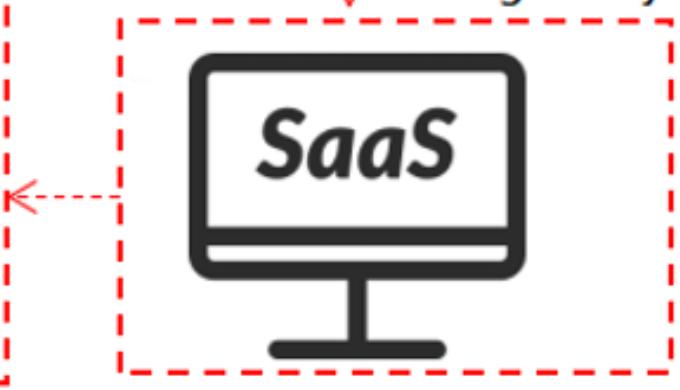

SaaS platform

Figure 3

Data acquisition and transmission system

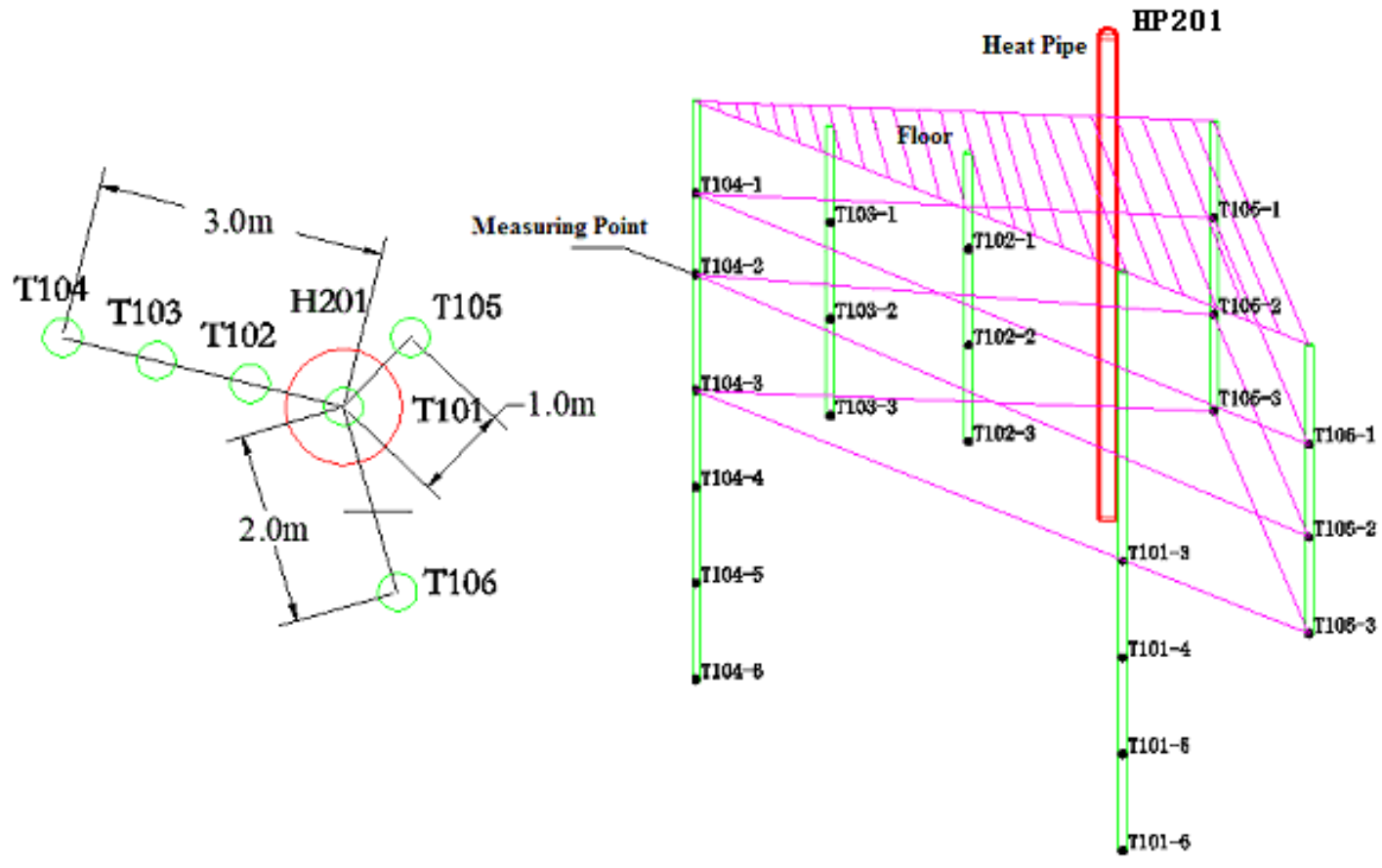

Figure 4

The first platform HP and temperature measurement point layout 

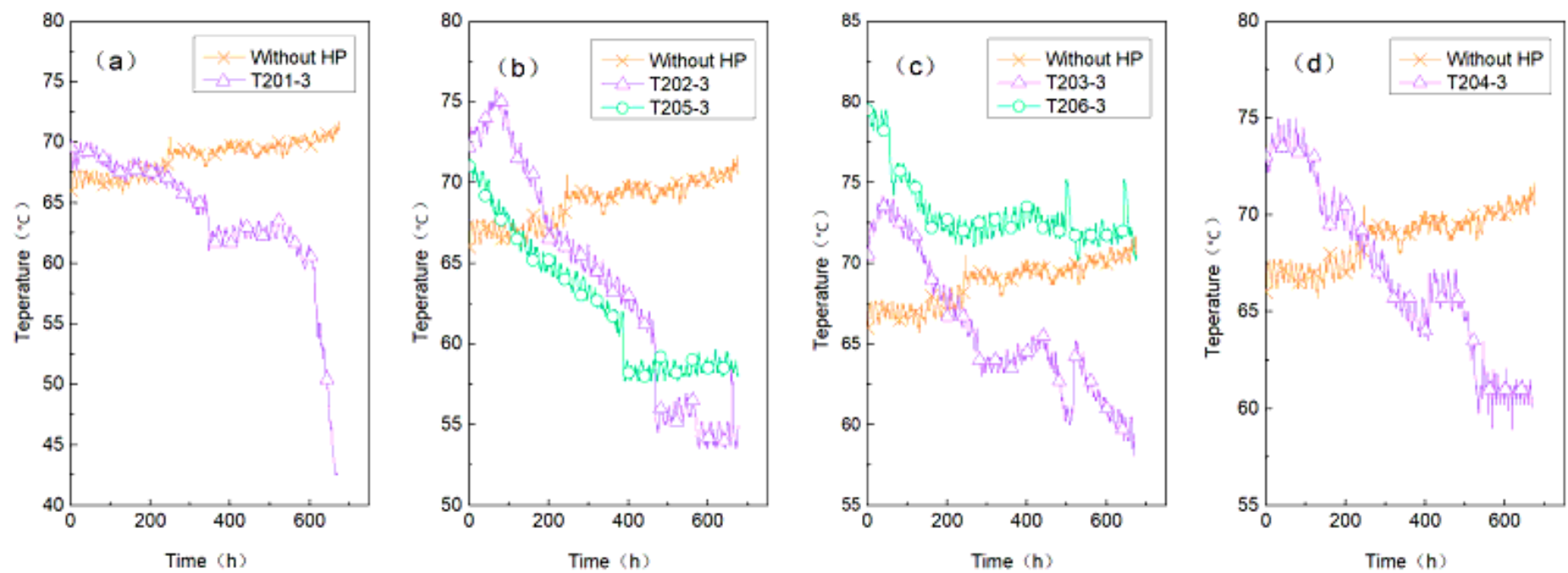

Figure 5

Comparison of the temperature with and without HP

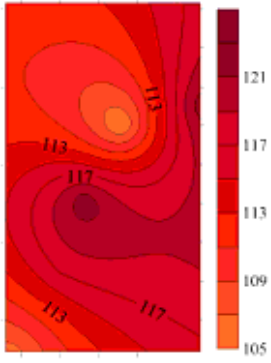

$1 \mathrm{~m}$

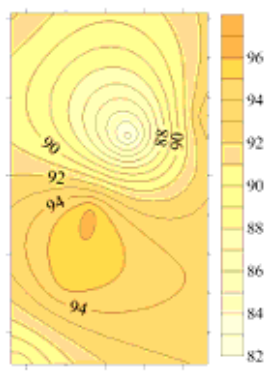

$1 \mathrm{~m}$

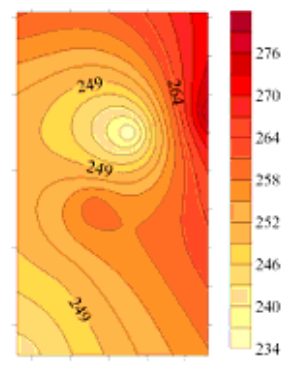

$2 m$

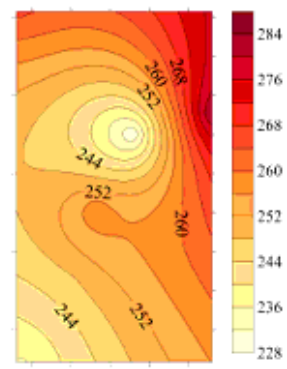

$2 m$

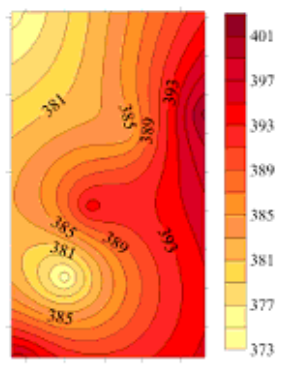

$3 m$

\section{(a) $0 \mathrm{~d}$}

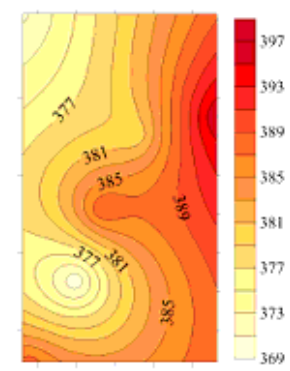

$3 m$

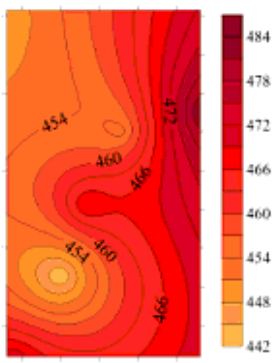

$4 m$

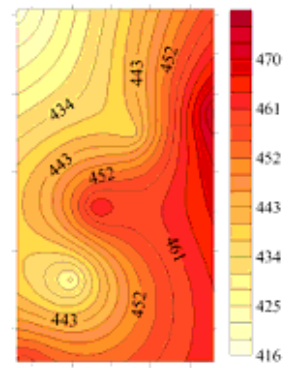

$4 m$

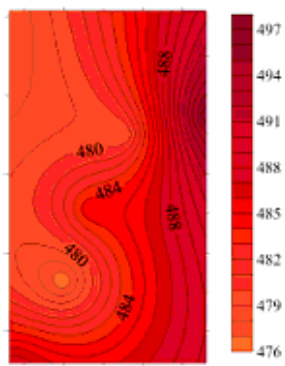

$5 m$

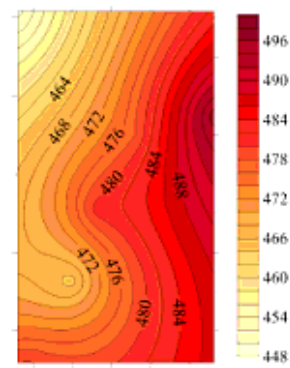

$5 m$

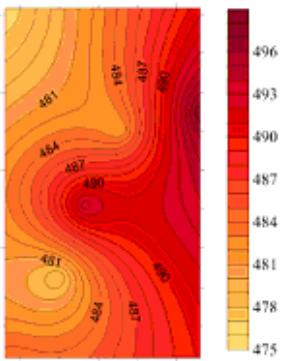

$6 m$

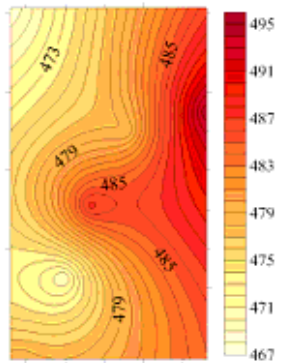

$6 m$

\section{(b) $90 \mathrm{~d}$}

\section{Figure 6}

Horizontal temperature distribution inside coal gangue dump of HP201 


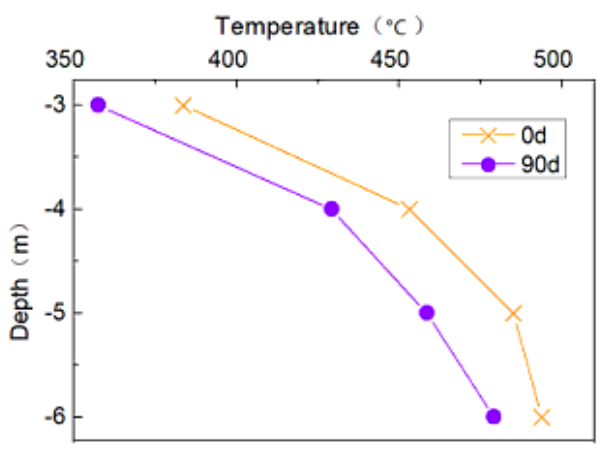

(a) $\mathrm{T} 101$

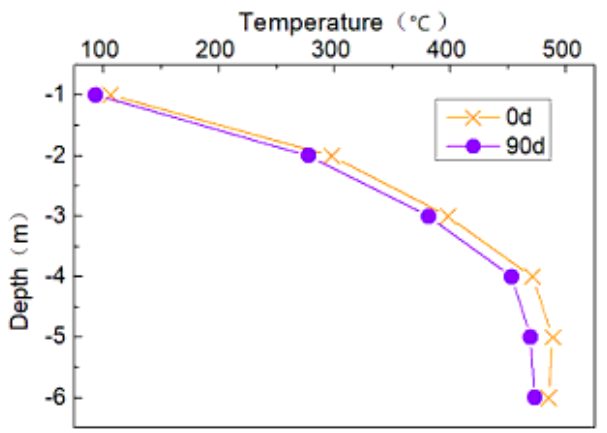

(d) $\mathrm{T} 104$

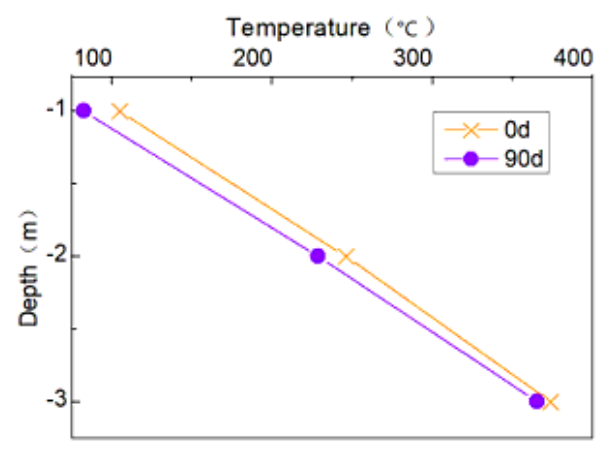

(b) T102

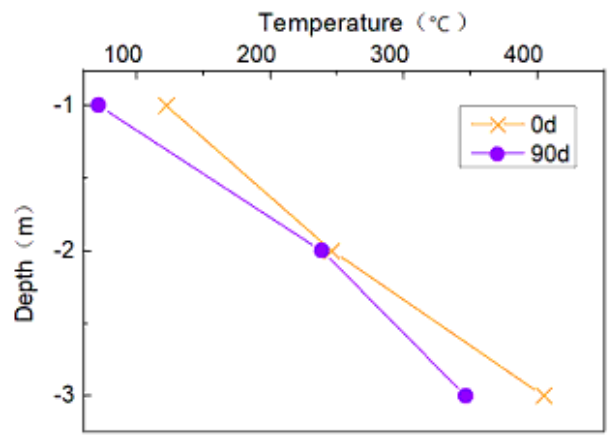

(e) T105

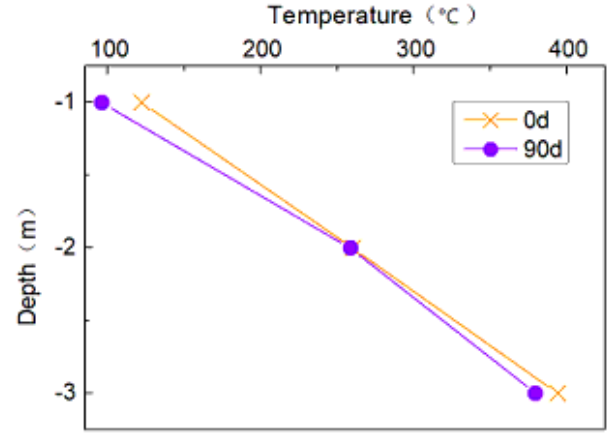

(c) T103

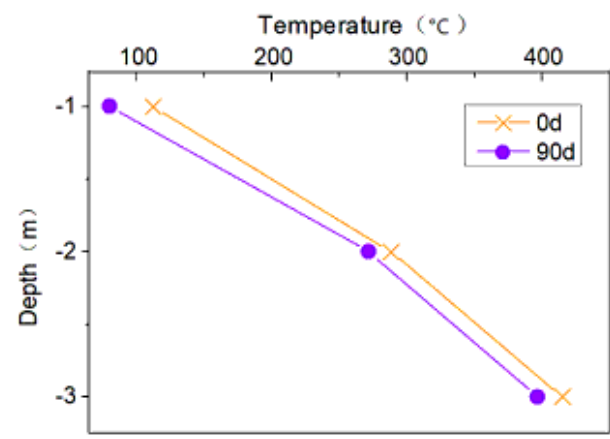

(f) $\mathrm{T} 106$

Figure 7

Vertical temperature distribution inside coal gangue dump of HP201 


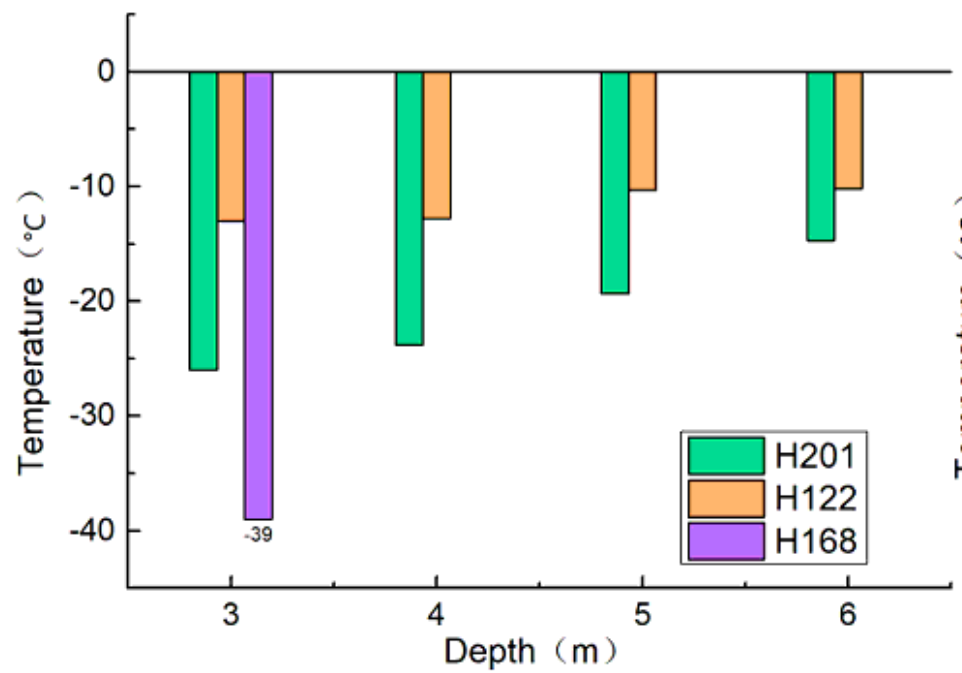

(a) Horizontal distance from HP 0m

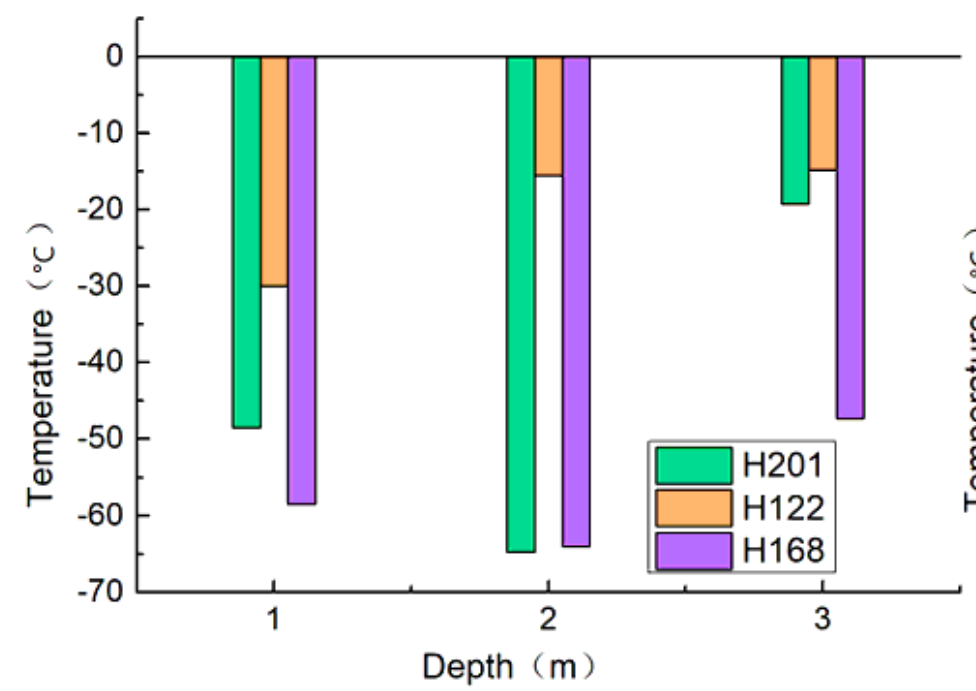

(c) Horizontal distance from HP 2m

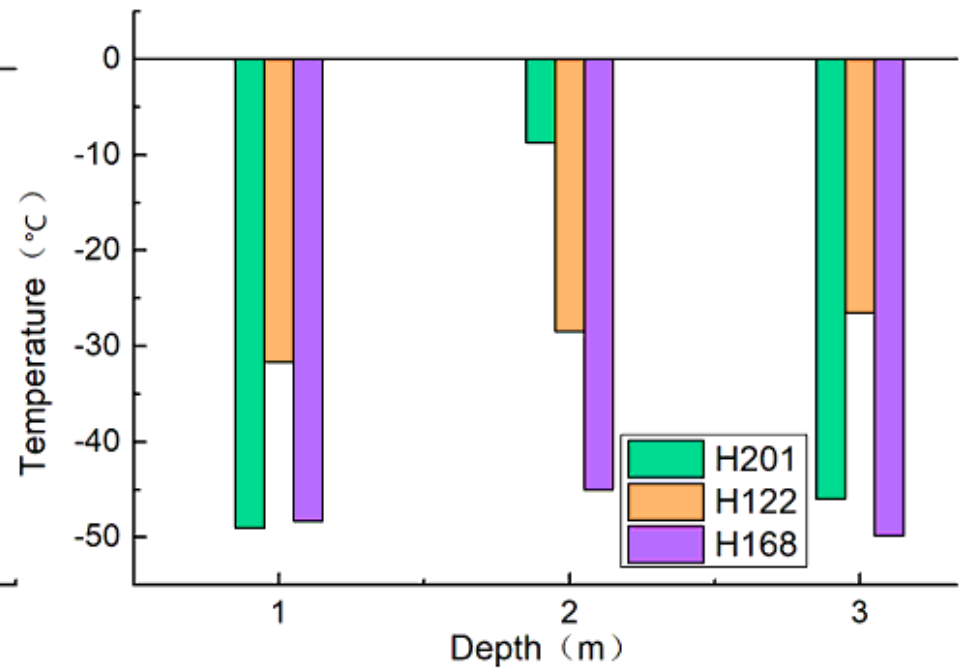

(b) Horizontal distance from HP $1 \mathrm{~m}$

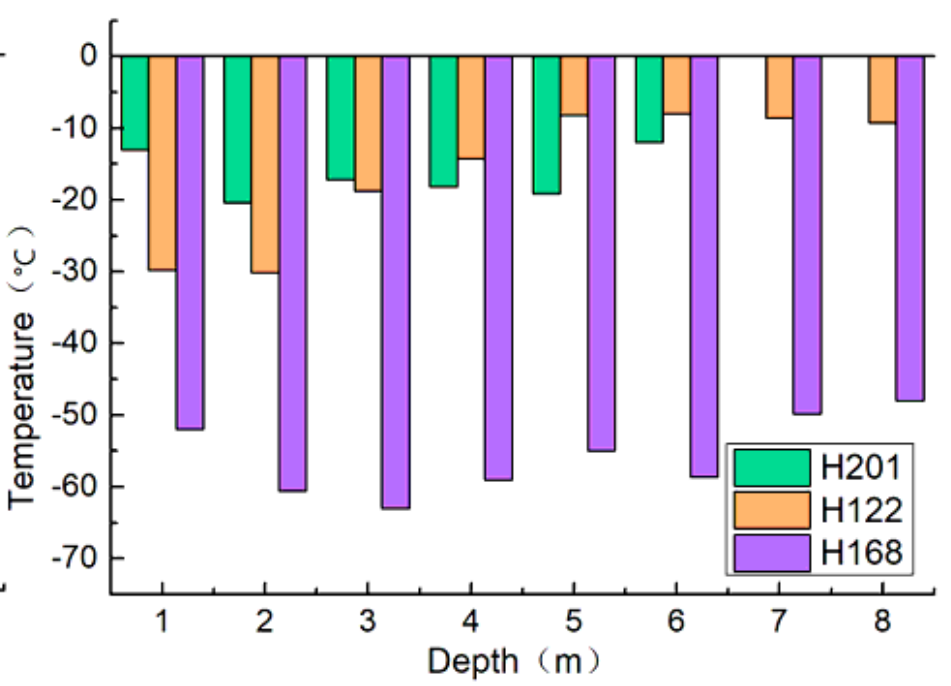

(d) Horizontal distance from HP 3 m

Figure 8

Temperature changes of three platforms at different depths under the action of HPs 